\title{
Risk and new technologies of rule
}

\section{Risco e novas tecnologias de regulação}

\author{
Maria João Militão Ferreira \\ Assistant Professor at the Instituto Superior de Ciências Sociais e Políticas/Universidade Técnica de Lisboa. \\ mjmfsp@gmail.com
}

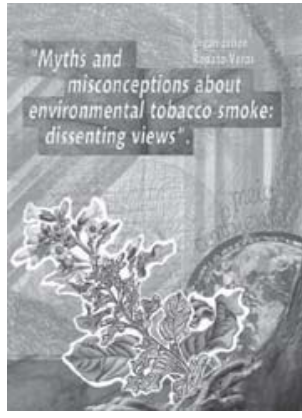

VERAS, Renato (Org.). Myths and misconceptions about environmental tobacco smoke: dissenting views. Translation Tais Leal de EdUerj; Unati, 2010. 60p. Oliveira. Rio de Janeiro:

$M$ yths and misconceptions about environmental tobacco smoke: dissenting views edited by Renato Veras (2010) is a collection of essays intended to critically address the way public smoking restrictions can be understood as embodying new technologies of rule in post-modern societies. The question raised is whether public ideologies that ban certain types of public behaviour, such as smoking, can be justified on behalf of collective public interests or can, rather, be defined as surveillance mechanisms that restrict individual freedom. At the heart of the publication is the concept of risk, and how such concept is employed by both experts and policy-makers in the definition of public health discourses that, in turn, reify public smoking as a deviant practice that should be banned from the social realm. In the provocative first essay "Misplaced targets: in defence of smokers", Castro Santos questions the neutrality of the supposedly scientific knowledge that, based on its epistemic authority, blames smokers for growing levels of cancer registered in modern societies. The author makes an appeal to sociology in order to resist such hegemonic epistemic discourse and upholds that new spaces of inclusive and not exclusive social interactions should be created. In another contribution to the collection, Veras strengthens such an appeal by stressing the contingency and constructed nature of risk perception. The author writes, "questioning is always a good exercise, particularly in respect of incomplete findings, or partial scientific evidence repeated again and again in order to transform them in "unconditional truth... sometimes low level risks are overestimated, while others much higher are underestimated" (p.45). As Geoffrey Kabat states, Castro Santos takes a position that is rarely articulated in intellectual arenas and that argues that the epidemiology and public health 'apparatus' have promoted an authoritarian and dogmatic discourse concerning tobacco use turning smokers into elements that or conform to normalised patterns of social behaviour or should be excluded from the social realm (p.29). In his own article, Kabat argues that there is an extremist strain in the anti-smoking movement that is based on biased scientific knowledge. The contingency of such knowledge is often forgotten in the "crusade to demonize smoking" to therefore turn "weak scientific findings" into "dogmas" difficult to deconstruct. However, 
Kabat also claims that it is necessary to seriously discuss what experts and publics know about the effects of smoking on health and how to inform people about how lifestyle factors may have an impact on health and longevity (p.35).

The discussion between the two authors as well as the contributions from other authors to the collection are placed in a very distinctive epistemological and ontological framework, namely the Foucauldian approaches to the question of risk and to modern technologies of rule that try to normalise social behaviour, promote self-surveillance and affirm experts as modern fact builders and risk tutors (Latour, 1987). The volume contributes to existing literature by the way it applies the analysis of modern technologies of rule to the debate on anti-smoking public policies.

The contributing authors to the collection refer to the question of risk, theorising it under the label of contingency. They depict the development of anti-smoking public policies as a response to the need to control the randomness of events affecting populations. Such response is materialised in what Foucault terms as "apparatuses of security". The author defines the concept of "apparatuses of security" through an articulation between several elements, namely the governance of accidental and random events and normalisation. In a Foucauldian sense, to govern means to find instruments to predict and manage questions deriving from eventual adverse conditions. This perspective stresses the importance of the circulation of causes and effects, the definition of risk factors and above all the construction of theoretical fields of knowledge that simultaneously uphold and are supported by power technologies (Foucault, 2007, p.34). Normalisation operates by establishing different degrees of the former (curves of normality) rather than fixed patterns of normality and abnormality. The lower degrees are then optimised through normalisation processes. In this context, optimisation means bringing the most unfavourable curves close to the most favourable ones (Foucault, 2007, p.63). The governance of accidental and random events, such as modern diseases and normalisation, are fundamental factors concerning the governance of advanced liberal democracies. Medicalisation of societies by normalising social behaviour has been a paradigm of modern practices of rule. In their contribution to the collection, Laguardia and Carrara state: "the general scheme of perception generated by the actual smoking war is very similar to what happened to sexually transmitted diseases during the most part of the 19th century, and that is still linked to Aids" (p.39).

Among the rationalities for governing advanced liberal democracies (Rose, 1996, 1998), a set of administrative and preventive strategies has emerged regarding the management of risk factors, whose effect is to "dissolve the notion of a subject or a concrete individual and put in its place a combinatory of factors, the factors of risk" (Castel, 1991, p.281). Concomitantly with what Rose (1998), has termed "government at a distance", such strategies help define population flows. The criteria for such definition follows the allocation of risk factors to certain groups, thus considered as potential threats. In his essay, Barros states that "at this moment, persecution in Brazil is against tobacco, and soon it will be against obesity, and the logic continues to be the same that led to the Vaccine Uprising in the beginning of the 19th century" (p.20). 
In this sense, strategies for government at a distance result in a distortion of the equilibrium between specialists and administrators that favour the latter, strengthening the abstract character inherent to the control of populations deemed as "communities of risk" (Rose, 1998), or "risk populations" (Castel, 1991). As Castel (1991) points, throughout the nineteenth century, dangerousness as an internal quality of the subject was substituted by the calculus of objective risks, defined by establishing correlations between statistical frequencies. In the move from dangerousness to risk, the latter becomes autonomous in relation to the former, when it is considered as deriving from the association of an abstract set of characteristics that might lead to risk behaviours, rather than from the holding of a precise danger by a particular individual. The abstract and purely probabilistic nature of the identification of risk factors paves the way for preventive strategies based on deduction and on new technologies of surveillance that install systemic prevention mechanisms. The distinctive character of such technologies is that they do not rely on individualisation but on generalisation, that is, on scientific pre-detection that works without the need for physical presence, since these kinds of technologies do not target the self but a merge of risk factors. Preventive strategies are thus able to construct the objective factors from where danger might derive and to act accordingly. The allocation of risk factors to specific groups eventually reflects traditional stratifications of social classes. Unlike the languages of social inequality and danger, the language of risk entails the endless amplification of risk, since "the entire population can be the locus of a vulnerability that can also single out specific populations, in a way that the language of danger, class or disadvantage cannot" (Dean, 1999, p.167). Also, the strategies for risk management are not thought to address economic and social inequalities, but specifically to deal with risk (Dean, 1999, p.167), creating for it a new political and social space. Such new political space gains momentum due to the contemporary need to erase contingency, namely the contingency associated with the risks inherent in simply being alive. Lucien Sfez, another contributor to the collection, argues: "the ideal of perfect health and immortality is in the majority of prophecies. We shouldn't be astonished to find it again as the main character in the utopias of the 21st century" (p.43).

If we bear in mind Foucault's conceptualisation of government, specifically the two meanings he attributes to it - government as an experience of the self and government as problematic of rule - we can understand the political consequences of this new risk space. Regarding the experience of the self, understood as the set of principles that orientate the conduct of others and of oneself through reflection or action, the passage from dangerousness to risk entails two consequences. First, the re-coding of distinctions between the included and the marginalised (Rose, 1996, p.340) and the subsequent practices towards the latter, either of further exclusion or of inclusion through policies specifically focused on overcoming deviant behaviours. Second, the emphasis upon personal responsibility regarding life styles with direct consequences upon the social risk management. On the subject of the war against smoking, Birman writes that "what stands out in the Brazilian law field is the draconian mark in the characterization of smokers as tainted... the smoker is the impersonation of taint and dirt, being brutally rejected in the public space" (p.24). Technocratic rationalities are articulated into calculated and pragmatic government 
strategies that explore and reify to the limit the possibilities for identification and subsequent management of risk factors. Such factors, whether endogenous or exogenous to the subject, serve the translation of political programmes, in this case the "hygienist utopia" (Castel, 1991, p.289) of full community security and prosperity, into forms of exercising authority over persons regarding their practices and beliefs (Rose, 1996, p.43). Risk management is achieved by establishing relations of control that, working at a distance, articulate between governmental and non-governmental apparatuses and institutions, such as epidemiological epistemic communities. The latter is entrusted with the responsibility for risk management, demanding their transformation in the sense that these institutions have to be 'made auditable', which calls for the instalment of accountability devices. It is a technique particularly well-suited for the government at a distance since "it travels well across space and time, is capable of being propagated in a multitude of locales, channelling and organizing activities and linking centres of calculation to sites of implementation according to new vectors" (Rose, 1996, p.55). It is also a technique congruent with the breaking of the direct relationship between the subject and the caring expert, and the subsequent dissociation between the roles of technicians and administrators, that Castel (1991, p.287)has identified in psychiatric, medical and social work professions and that he considers essential in the transition from dangerousness to risk.

In the backdrop of Foucauldian approaches lies the assumption that advanced liberalism has again changed the articulation between risk and individual responsibility. In the wake of a "new prudentialism" (O'Malley, 1996), risk management, understood as a social and a governmental technology, has become more complex. Such complexity derives from a displacement of responsibility from the state back to the individual. It is therefore congruent with characteristics already mentioned concerning "government at a distance" and technologies of the self. In the last essay of the collection, Zaluar and Castro Santos write "a new concept, dressed up in sociological, legal and medical clothes, has been praised as the 'precautionary principle', a precept used to defend public health policies by governments all over the world, even in the absence of clear scientific evidence" (p.55). The devolution of the responsibility for risk management to the individual enhances not only the privatisation of risk control, but also other tendencies associated with the retreat of the welfare state. Together with the promotion of prudent behaviour in subjects, the enhancement of utilitarian, calculative and consequentialist strategies for self-conduct are intensified. This is important for in what concerns the concept of risk itself prudentialism represents a turning point, since in practice this 'new prudentialism' multiplies and expands to the limit the areas to be monitored though risk controlling strategies. Concomitantly with the multiplication of areas and groups deemed at risk, the production of risk as a continuum is a grey area identified either by observable indicators or by invisible correlations of pre-determined variables (Dean, 1999, p.167). Therefore, risk is always present within the social realm, since the entire population is a possible target for risk prevention strategies. 


\section{REFERENCES}

CASTEL, Robert.

From dangerousness to risk. In: Burchell, Gordon; Graham, Colin; Miller, Peter (Ed.). The Foucault effect: studies in governmentality. Chicago: The University of Chicago Press. p.281-299.1991.

DEAN, Mitchell.

Governmentality: power and rule in modern society. London: Sage. 1999.

FOUCAULT, Michel.

Security, territory, population: lectures at the College de France, 1977-1978. Basingstoke: Palgrave Macmillan. 2007.

LATOUR, Bruno.

Science in action: how to follow scientists and engineers through society. Cambridge: Harvard University Press. 1987.
O'MALLEY, Pat.

Risk and responsibility. In: Barry, Andrew; Osborne, Thomas; Rose, Nikolas (Ed.). Foucault and political reason: liberalism, neo-liberalism and rationalities of government. Chicago: University of Chicago Press. 1996.

ROSE, Nikolas.

Inventing our selves: psychology, power, and personhood. Cambridge: Cambridge University Press. 1998.

ROSE, Nikolas.

Governing 'advanced' liberal democracies. In: Barry, Andrew; Osborne, Thomas; Rose, Nikolas (Ed.). Foucault and political reason: liberalism, neo-liberalism and rationalities of government. Chicago: University of Chicago Press. p.37-65. 1996. 